\title{
Big Problems from Little Kidneys
}

\author{
A review of: Keller G, Zimmer G, Mall G, Ritz E, Amann K 2003 Nephron number in patients with hypertension
} N Engl J Med 348:102-108

$\mathrm{D}$ EVELOPMENT OF THE human kidney begins at about 5 weeks fetal age when the ureteric bud, an outpouching of the nephric duct, grows into the metanephric mesenchyme and begins to branch. Iterative interactions between each new branch tip and the adjacent mesenchyme generate the nephrons of each kidney. At birth, this crop of nephrons hangs like fruit on branches of the arborized collecting system and constitutes the individual's nephron endowment for life. Occasionally, when the process goes awry, neonates may be born with obvious hypoplasia (1:400) or aplasia (1:3600) of at least one kidney $(1,2)$. Very rarely, children are born with hereditary syndromes (e.g., renalcoloboma syndrome) in which congenital bilateral nephron deficit is associated with progressive renal insufficiency $(1,3)$.

While our medical paradigms easily accommodate these developmental "errors", we tend to accept as "normal" the wide variance in nephron number ( 0.3 to 2.0 million nephrons per kidney) reported from autopsies of adults who die from non-renal causes $(4,5)$. Yet, since 1988, Brenner and colleagues have challenged this notion, proposing that "normal" humans born at the lower end of the nephron endowment scale are predisposed to "essential" hypertension (6). They hypothesized that signals driving compensatory hypertrophy of the few overworked nephrons cause glomerulosclerosis and a cycle of subtle, slowly progressive renal dysfunction (7). Their hypothesis is supported by studies showing lower nephron number in inbred hypertensive rats compared to normotensive control strains (8) and showing that longevity of transplanted rat kidneys was influenced by allograft nephron number (9). However, it has been understandably difficult to gather evidence that suboptimal nephron endow-

\section{PAUL GoOdYer}

ment has any clinical consequence for the "normal" human population.

In this context, the recent article by Keller et al. (10) is important. The authors used a careful, well-validated method for measuring whole-kidney nephron number in autopsies on 10 German subjects with clear evidence of primary hypertension vs 10 control subjects, closely matched for gender, age, height and weight. The subjects were less than 60 years old, after which glomerular obsolescence might confound the issue. On average, the hypertensive subjects had $46.6 \%$ fewer nephrons per kidney than controls. The kidneys of hypertensive subjects also had larger glomeruli (glomerular volume $=233 \%$ of controls) - enough compensatory hypertrophy to restore total glomerular volume per kidney to baseline. As predicted by Brenner's hypothesis linking suboptimal nephron number, compensatory glomerular hypertrophy and progressive glomerular damage, there was also more glomerulosclerosis in the affected kidneys (5.5\% vs. $0 \%$ ).

Although their patient sample was small, the observations by Keller et al. provide clear support for Brenner's hypothesis and demand our attention. Children born with fewer nephrons may not only be at greater risk for essential hypertension but presumably have less renal reserve to contend with diabetes, glomerulonephritis and other acquired nephropathies later in life. Recently it was shown that low birth weight $(<2.5$ $\mathrm{kg}$ ) is associated with a $13 \%$ reduction in nephron number (11). Perhaps even more significant is the observation in rodents that nephron number is reduced (20\%) by moderate maternal vitamin A deficiency (12). If this observation is translatable to humans in developing countries such as India (population $=1$ billion), where up to $20 \%$ of pregnant women are vitamin A deficient, the public health implications of a nutritional cause for suboptimal nephron endowment are staggering.

1. Hiraoka M, Tsukahara H, Ohshima Y, Kasuga K, Ishihara Y, Mayumi M 2002 Renal aplasia is the predominant cause of congenital solitary kidneys. Kidney Int 6:1840-1844

2. Parikh CR, McCall D, Engelman C, Schrier RW 2002 Congenital renal agenesis: case control analysis of birth characteristics. Am J Kidney Dis 39:689-694

3. Porteous S, Torban E, Cho NP, Cunliffe H, Chua L, McNoe L, Ward T, Souza C, Gus P, Giugliani R, Sato T, Yun K, Favor J, Sicotte M, Goodyer P, Eccles M 2000 Primary renal hypoplasia in humans and mice with PAX2 mutations: evidence of increased apoptosis in fetal kidneys of Pax2 (1Neu) +/- mutant mice. Hum Mol Genet 9:1-11

4. Gundersen HJ, Bagger P, Bendtsen TF, Evans SM, Korbo L, Marcussen N, Moller A, Nielsen K, Nyengaard JR, Pakkenberg B, et al. 1988 The new stereological tools: dissector, fractionator, nucleator and point sampled intercepts and their use in pathological research and diagnosis. APMIS 96:857-881

5. Nyengaard JR, Bendtsen TF 1992 Glomerular number and size in relation to age, kidney weight, and body surface in normal man. Anat Record 232:194-201

6. Brenner BM, Garcia DL, Anderson S 1988 Glomeruli and blood pressure: less of one, more the other? Am J Hypertens 1:335-347

7. Mackenzie HS, Lawler EV, Brenner BM 1996 Congenital oligonephropathy: The fetal flaw in essential hypertension? Kidney Int Suppl 55:S30-34

8. Skov K, Nyengaard J, Korsgaard N, Mulvany MJ 1994 Number and size of glomeruli in spontaneously hypertensive rats. J Hypertens 12:1373-1376

9. Azuma H, Nadeau K, Mackenzie HS, Brenner BM, Tilney NL 1997 Nephron mass modulates the hemodynamic, cellular, and molecular response of the rat renal allograft. Transplantation 63:519-528

10. Keller G, Zimmer G, Mall G, Ritz E, Amann K 2003 Nephron number in patients with hypertension. N Engl J Med 348:102-108

11. Manalich R, Reyes L, Herrera M, Melendi C, Fundora I 2000 Relationship between weight at birth and the number and size of renal glomeruli in humans: a histomorphometric study. Kidney Int 58:770-773

12. Gilbert T, Merlet-Benichou C 2000 Retinoids and nephron mass control. Pediatr Nephrol 14:1137-1144

\section{McGill University and}

Montreal Children's Hospital

Division of Pediatric Nephrology

2300 Tupper Street, Room E222B

Montreal, Quebec H3H 1 P3

Canada

e-mail: paul.goodyer@muhc.mcgill.ca

DOI: 10.1203/01.PDR.0000082992.69946.62 